Discussion Paper No. 837

\title{
INTERNATIONAL HARMONIZATION OF THE PATENT-ISSUING RULES
}

\author{
Kaz Miyagiwa \\ Yuka Ohno
}

March 2012

The Institute of Social and Economic Research Osaka University

6-1 Mihogaoka, Ibaraki, Osaka 567-0047, Japan 


\title{
International Harmonization of the Patent-Issuing Rules
}

\section{Kaz Miyagiwa and Yuka Ohno*}

\begin{abstract}
:
With the America Invents Act of 2011, the U.S. changed its patent-issuing rule from first-toinvent to first-to-file, the international norm. We investigate the effect of such a policy change in a two-country model of R\&D competition for two sequential (basic and final) inventions. We find that a switch never speeds up basic research. A delay is more likely especially in industries where the final product generates more value in the U.S. Simulations show that a delay in basic research also retards final invention, decreasing world welfare.
\end{abstract}

JEL Classification numbers: F1, O3

Keywords: TRIPS, first-to-file, first-to-invent, international patent law harmonization, sequential innovation, $R \& D$ competition

Contact: Yuka Ohno, Dept. of Economics, Hokkaido University, Kita 9 Nishi 7, Sapporo 0600809, Japan, Phone \& Fax: +81-11-706-3989, E-mail: Yuka_Ohno@econ.hokudai.ac.jp

\footnotetext{
* Miyagiwa: Kobe University and Emory University. Ohno: Hokkaido University. We thank participants at the 2011 Econometric Society meetings (Seoul), the 2010 APTS meetings (Osaka), and the seminar at Kobe University for comments. Miyagiwa acknowledges the research grant from Microsoft's Academic Research Program. Errors and opinions expressed are the authors'.
} 


\section{Introduction}

Since the 1883 Paris Convention, there have been considerable efforts being made to harmonize patent laws internationally, culminating in the conclusion of the Agreement on TradeRelated Aspects of Intellectual Property Rights (TRIPs) under the auspices of the WTO. ${ }^{1}$ However, patent law still remains independently administered and enforced by each country, creating substantial administrative, financial, and legal costs to multinational corporations operating in technologically sensitive industries.

The present paper focuses on one important difference in patent law administration between the U.S. and the rest of the world. When two persons apply for a patent on virtually identical inventions, the patent issues to the person who filed his application first. This simple rule, however, does not apply in the U.S., where instead the patent issues to the person who demonstrates to have discovered the invention first. After decades of resisting reform, the U. S. finally enacted the America Invents Act of 2011 so as to formally switch to a first-to-file ("FTF”) system on March 16, 2013.

This policy change however is not without a controversy. The opposition to patent law reform in the U.S. has argued that its first-to-invent ("FTI") rule is designed to protect small inventors, who take a longer time to prepare patent applications compared with major corporate inventors. On closer inspection, however, this argument does not hold much water today. First, the recent patent law reform in the U.S. has created a new provisional patent application, which is much simpler to file. ${ }^{2}$ Second, in the current U.S. FTI system, disputes over priority of invention must be settled in a legal proceeding called "interference,” which involves examining laboratory logbooks, establishing dates for prototypes, and so forth at a hearing before the USPTO (U.S.

\footnotetext{
${ }^{1}$ http://www.wto.org/english/tratop_e/trips_e/intel2_e.htm. Also see Moser (2005) for a general view on patents and innovation.

${ }^{2}$ See Lerner (2003).
} 
Patent and Trademark Office) Board. ${ }^{3}$ In one estimate the mean adjudication cost of interference stands at \$656,306 (Hart 2007). Since interference costs are borne equally by the parties involved, the FTI rule does not necessarily protect financially constrained small inventors. The fact that interference does not help small individual inventors against large corporations is confirmed in an empirical study of Cohen and Ishii (2005). ${ }^{4}$

Despite these counterarguments, the opposition often adduces the undeniable fact that the U.S. has led the world in R\&D for more than a century and attributes it to the FTI feature of its patent law that has existed since $1836 .{ }^{5}$ Although the opposition has offered no logical connection between these facts, Lo and Sutthiphisal (2009) find that, when Canada made a similar switch from FTI to FTF in 1989, Canadian R\&D efforts actually fell. Thus, it seems a bit premature to dismiss the opposition's argument outright. More importantly, since the U.S. economy is substantially larger than the Canadian counterpart, it is possible that the U.S. decision to adopt a FTF rule has far greater ramifications on worldwide R\&D activities.

The objective of the present paper therefore is to formally evaluate the worldwide effect of the U.S. decision to switch from FTI to FTF. To that end, we develop a dynamic model of $\mathrm{R} \& \mathrm{D}$ in which two firms compete to develop a product in a two-country world, the U.S. and the rest of the world. Product development takes two sequential inventions, i.e., basic technology and its commercialization or application design. Both inventions are assumed risky. Specifically, the hazard rates for the first invention depend on firms' investments in $R \& D$ whereas those for the second are exogenous. This reflects our belief that basic research is more sensitive to firms' capital outlays relative to its commercialization.

\footnotetext{
${ }^{3}$ See Cohen and Ishii (2005) for a detailed study of the interference process.

${ }^{4}$ Cohen and Ishii (2005) also find that, contrary to folklore, most patent races are among major corporate research laboratories chasing well-defined research topics.

${ }^{5}$ For example, "It should be understood that it is because the U.S. has a first to invent structure and the rest of the world has a first to file structure that the U.S. is the production and employment machine that it is." (See http//www.piausa.org/layout/set/print/patent_reform_issue.)
} 
Finally, we assume both inventions are patentable separately in two countries. Our focus is on whether basic invention is to be patented. Patenting basic invention gives the inventor the exclusive right to it but intensifies $R \& D$ competition for final invention, while not patenting it exposes the inventor to the risk of losing that right when the rival also discovers basic invention before the inventor discovers final invention. We show that whether to patent basic invention hinges crucially on the patent-issuing rule prevailing in both countries.

Now, our main results can be stated. First, if invention A (basic technology) gets patented both before and after patent law harmonization, harmonization has no effect whatsoever. On the other hand, if A does not get patented before harmonization, then a switch to FTF in the U.S. decreases R\&D investments for basic research. ${ }^{6}$ We show that that scenario is more likely in industries where the final product generates more value inside the U.S.; for example, the pharmaceutical industry, where the U.S. leads the world with its share around $36 \% .{ }^{7}$ The semiconductor industry might be impacted similarly, since semiconductors are key components for modern consumer goods and aircraft manufacturing, two areas in which the U. S. is still dominant.

Even though basic research diminishes, it does not necessarily follow that final invention is delayed, because in a harmonized world the inventor, for instance, may choose to patent basic invention so that final invention is discovered sooner due to induced $\mathrm{R} \& \mathrm{D}$ competition for it. Due to such contrasting effects on basic and final inventions, the effect of a switch to FTF on total time needed to discover both inventions cannot be determined analytically in all cases. In such a case, our simulations show that a switch to FTF delays discovery of final invention for all the relevant parameter values we consider.

\footnotetext{
${ }^{6}$ An exception is when firms file for a patent both before and after patent law harmonization, in which case, a switch to FTF has no effect whatsoever on R\&D investments and welfare.

${ }^{7}$ Standard \& Poor's, Industry Surveys - Healthcare: Pharmaceuticals, June 2, 2011.
} 
Given the above results, it is then possible to make a welfare analysis. If consumers value only final invention, a delay in its discovery decreases consumer welfare. In this case, our simulations show that expected firm profits also fall for the same parameter values. With lower consumer surplus and firm profits, we conclude that world welfare falls.

To the best of our knowledge, this is the first paper that formally studies the effect of international harmonization of the patent-issuing rules. Scotchmer and Green (1990) also compare the two rules, but they consider a single-country setting, leaving unexamined the effect of patent law harmonization and its characterizations in terms of country/market attributes as discussed here. More importantly, they assume fixed hazard rates for both basic and final inventions, thereby leaving unanswered the question how harmonization affects R\&D incentives.

The remainder of the paper is organized in five sections. The next section presents the model in detail. In sections 3 we depict a non-harmonized world, in which the U.S. uses a FTI rule while the rest of the world uses a FTF rule. In section 4 we turn to a harmonized world, in which both countries use FTF rule. In section 5 we compare the equilibrium levels of investment in R\&D between the two. We conclude in section 6 .

\section{Model setup}

We consider a patent race between two agents for two inventions A and B. Inventions are sequential in that invention A must be discovered before invention B. Thus, invention A may represent a basic technology while invention B its application or commercialization.

Let $\alpha \mathrm{V}$ and $\beta \mathrm{V}$ denote the worldwide values of inventions $\mathrm{A}$ and $\mathrm{B}$, respectively, where $\alpha, \beta>0, \alpha+\beta=1$, and $\mathrm{V}$ represents the total value of the two inventions. ${ }^{8}$ Inventions $\mathrm{A}$ and $\mathrm{B}$ are independently patentable in each country. There are no application fees or any other fees for

\footnotetext{
${ }^{8}$ Several authors [e.g., Chang (1995) and Kao (2009)] have used Nash bargaining to determine these shares. Since this has nothing to do with harmonization, we abstract from it and treat these weights as exogenous. Also, the weights $\alpha$ and $\beta$ are assumed common across countries.
} 
determination of priority and a patent is issued immediately when an application is filed. Let $\mathrm{V}_{\mathrm{u}}$ and $\mathrm{V}_{\mathrm{w}}$ denote the total valuations of the inventions in two countries, country $\mathrm{u}$ (= the U.S.) and country $\mathrm{w}$ (= the rest of the world), respectively, so that $\mathrm{V} \equiv \mathrm{V}_{\mathrm{u}}+\mathrm{V}_{\mathrm{w}}$. With this system of notation we can write, for example, the value of the patent on A in the U.S. as $\alpha V_{u}$, and the value of the patents on $\mathrm{B}$ in two countries as $\beta \mathrm{V}=\beta\left(\mathrm{V}_{\mathrm{u}}+\mathrm{V}_{\mathrm{w}}\right)$.

The model is set in an infinite time horizon, where time flows continuously from zero. At time $t=0$, two symmetric agents start an $R \& D$ race for invention $A$. $R \& D$ is risky in that a discovery date $\tau_{\mathrm{A}}$ of invention $\mathrm{A}$ is stochastic, with distribution given by;

$$
\operatorname{Prob}\left(\tau_{\mathrm{A}} \leq \mathrm{t}\right)=1-\exp \left[-\mathrm{g}\left(\mathrm{x}_{\mathrm{i}}\right) \mathrm{t}\right]
$$

Here, $\mathrm{g}\left(\mathrm{x}_{\mathrm{i}}\right)$, agent i's hazard rate function, is strictly concave in $\mathrm{x}_{\mathrm{i}}$, agent i's $\mathrm{R} \& \mathrm{D}$ investment, and satisfy Inada conditions. Two agents' discovery dates are independently distributed. Further, marginal R\&D cost is assumed constant at one so $\mathrm{x}_{\mathrm{i}}$ denotes the cost of investment. ${ }^{9}$

Given the setup, one agent eventually discovers $\mathrm{A}$ at a random date $\tau_{\mathrm{A}}$. Call this agent a "leader" and the other a "follower." For clarity of exposition we refer to a leader by the feminine pronouns and a follower by the masculine pronouns. As soon as a leader is identified, she immediately starts $R \& D$ for invention B. Assume that a discovery date $\tau_{B}$ of invention $B$ is exponentially distributed with constant hazard rate $\lambda$ :

$$
\operatorname{Prob}\left(\tau_{B} \leq t\right)=1-\exp (-\lambda t)
$$

These assumptions may be reasonable if $\mathrm{B}$ is commercialization of A and depends more on trials and errors than the size of outlays in R\&D facilities. Further, given the constant hazard rate, there is no loss of generality in assuming zero $R \& D$ cost for invention $B$.

When A is invented, the follower hears about it possibly through the media, but the information provided is insufficient for the follower to start $R \& D$ towards $B$, unless $A$ is patented. Thus, by not patenting A, the leader can make a head start towards B unthreatened by

\footnotetext{
${ }^{9}$ These features are standard in the literature; see Lee and Wilde (1980).
} 
rivalry. However, that also exposes the leader to the risk of losing the exclusive right to A if the follower discovers A before she discovers B. This tradeoff must be taken into consideration when the leader decides whether to patent A. Her decision depends in part on the type of patent-issuing rule prevailing in each country.

\section{A world without patent law harmonization}

In this section we consider a world without patent law harmonization, namely, the U.S. uses FTI while the rest of the world uses FTF. However, we begin with the analysis of competition for the leadership in a general setting, where $\Pi_{L}$ and $\Pi_{F}$ denote the (expected) profits from becoming a leader and a follower, respectively, evaluated at the date of discovery of A. The exact values of $\Pi_{L}$ and $\Pi_{F}$ depend on the equilibrium of the specific game considered and will be determined later in this section.

\section{A. Racing to be the leader}

At time zero, two agents begin a race for invention A. Suppose that they reach time $t>0$ without success, which occurs with probability $\exp \left[-\left(g\left(x_{i}\right)+g\left(x_{j}\right)\right) t\right]$, $(i \neq j)$. Conditional on that, agent i becomes a leader with probability $\mathrm{g}\left(\mathrm{x}_{\mathrm{i}}\right) \mathrm{dt}$, and a follower with probability $\mathrm{g}\left(\mathrm{x}_{\mathrm{j}}\right) \mathrm{dt}$ during the short time interval dt. Thus, agent i's (conditional) expected net profit at $t$ is $\exp \left[-\left(g\left(x_{i}\right)+\right.\right.$ $\left.\left.g\left(x_{j}\right)\right) t\right]\left[g\left(x_{i}\right) \Pi_{L}+g\left(x_{j}\right) \Pi_{F}-x_{i}\right] d t$. Integrating this expression over $t$ yields the expected profit to agent i given by;

$$
\int_{0}^{\infty} \exp (-r t) \exp \left[-\left(g\left(x_{\mathrm{i}}\right)+g\left(x_{\mathrm{j}}\right)\right) t\right]\left\{g\left(x_{\mathrm{i}}\right) \Pi_{\mathrm{L}}+g\left(x_{\mathrm{j}}\right) \Pi_{\mathrm{F}}-x_{\mathrm{i}}\right\} d t,
$$

where $r$ is the interest rate. Evaluating this integral yields;

$$
\frac{g\left(x_{i}\right) \Pi_{L}+g\left(x_{j}\right) \Pi_{F}-x_{i}}{r-g\left(x_{i}\right)-g\left(x_{j}\right)} .
$$

Agent $\mathrm{i}$ chooses $\mathrm{x}_{\mathrm{i}}$ to maximize this profit. The first-order condition is arranged to yield 


$$
g^{\prime}\left(x_{i}\right)\left[r \Pi_{L}+x_{i}+g\left(x_{j}\right)\left(\Pi_{L}-\Pi_{F}\right)\right]-\left(r+g\left(x_{i}\right)+g\left(x_{j}\right)\right)=0 .
$$

A Nash equilibrium $\left(\mathrm{x}_{\mathrm{i}}, \mathrm{x}_{\mathrm{j}}\right)$ simultaneously solves the pair of the first-order conditions. The symmetric equilibrium where $x=x_{i}=x_{j}$ satisfies

$$
g^{\prime}(x)\left[r \Pi_{L}+x+g(x)\left(\Pi_{L}-\Pi_{F}\right)\right]-(r+2 g(x))=0 .{ }^{10}
$$

This equation identifies two factors determining the equilibrium $R \& D$ investments. One is the profit $\Pi_{L}$ from becoming the leader. The other is $\left(\Pi_{L}-\Pi_{F}\right)$, the leader-follower profit differential. R\&D investment is motivated by the profit from being the leader but in a two-agent race it is also important not to be the follower. As can be easily checked, increases in both quantities stimulate investments in $R \& D$. We note this fact in

Lemma 1: (i) Given $\left(\Pi_{L}-\Pi_{F}\right), \partial x / \partial \Pi_{L}>0$; (ii) given $\Pi_{L}, \partial x / \partial\left(\Pi_{L}-\Pi_{F}\right)>0$.

\section{B. Racing for invention $B$}

Once the leader is identified, what follows next is best explained in terms of figure 1 . When $\mathrm{A}$ is discovered, the leader is at the first node in figure 1 , where she decides whether to patent A. There, she has four choices: patenting A in both countries, in either country or in neither country. However, since a patent in one country discloses all the information about invention A to the follower, there is no advantage in getting a patent in just one country. ${ }^{11}$ This narrows down the leader's options to just two: patenting A in both countries or not patenting it in either country.

Patenting A, the leader allows the follower to join an $\mathrm{R} \& \mathrm{D}$ race towards $\mathrm{B}$, where each can discover it with the equal probability $\lambda \mathrm{dt}$ over a short interval dt. If she wins this race, the leader owns both inventions worth V. If she loses the race, she still holds the patent on A worth $\alpha \mathrm{V}$. Thus, the leader's (conditional) expected profit evaluated at time $t$ is given by:

\footnotetext{
${ }^{10}$ The second-order conditions hold globally.

${ }^{11}$ Of greater practical importance is the fact that an inventor who gets a patent in one country must file for a patent in other countries within twelve months; failing to do so is interpreted as forfeiting the patent rights in other countries.
} 


$$
\pi_{\mathrm{PH}}=\frac{\lambda V(1+\alpha)}{r+2 \lambda}
$$

where the subscript PH reads "patent holder." Turning to the follower, if he wins the race, he earns $\beta V$ as he gets the patent on $B$; if he loses it, he gets nothing. So by an analogous procedure the profit to the follower equals:

$$
\pi_{\mathrm{NP}}=\frac{\lambda \beta V}{r+2 \lambda}
$$

where NP indicates “non-patent holder”.

Alternatively, consider what happens if the leader does not patent A. Then, she alone proceeds to discover B while the follower still tries to invent A. If she wins this asymmetric race, the game ends with her getting $\mathrm{V}$ and the follower getting nothing, as indicated in figure 1 . If the follower wins instead, he gets to decide whether to patent A.

If the follower patents A, the leader will surely challenge him in the U.S., where the FTI rule is in use. She can establish priority of invention and get the patent worth $\alpha V_{u}$ so the follower holds the patent only in the rest of the world, worth $\alpha \mathrm{V}_{\mathrm{w}}$. And both agents move on to compete a symmetric race towards $\mathrm{B}$, with a winner picking up the additional profit $\beta \mathrm{V}$. Therefore, if he patents A, the follower faces the expected profit

$$
\pi_{\mathrm{FW}}=\frac{\lambda\left(2 \alpha V_{\mathrm{w}}+\beta V\right)}{r+2 \lambda}
$$

whereas the leader expects the profit

$$
\pi_{\mathrm{LU}}=\frac{\lambda\left(2 \alpha V_{\mathrm{u}}+\beta V\right)}{r+2 \lambda}
$$

Consider next what happens if the follower does not patent A. Then, play moves back to the leader, who decides whether to patent A, knowing that the follower has caught up to her. If she patents $\mathrm{A}$, she gets the expected profit $\pi_{\mathrm{PH}}$ as the patent holder while the follower gets $\pi_{\mathrm{NP}}$. If she does not, then invention A remains unpatented while both agents try to invent B. If the leader 
wins this race, she gets patents on both A and B worth V. Even if she loses it, she will still get the patent on A in the U.S. Thus, the leader's expected profit is

$$
\pi_{\mathrm{LN}}=\frac{\lambda\left(\alpha V_{\mathrm{u}}+V\right)}{r+2 \lambda}
$$

Alternatively, if the follower wins the race towards B, he gets all the patents except on A in the U.S., so his expected profit is $V-\alpha V_{u}$. If he loses the race, he gets nothing. Thus, the follower's expected profit is

$$
\pi_{\mathrm{FN}}=\frac{\lambda\left(V-\alpha V_{\mathrm{u}}\right)}{r+2 \lambda}
$$

\section{C. Equilibrium path}

We now solve the model backward. Consider the leader's second node in figure 1 . If she patents A there, her expected profit is $\pi_{\mathrm{PH}}$. If she does not, her expected profit is $\pi_{\mathrm{LN}}$. Since $\pi_{\mathrm{PH}}>$ $\pi_{\mathrm{LN}}$ the leader patents A. This is intuitive. Since the follower has discovered A, there is no reason to hide the information about A. When we move back to the follower's node, the same intuition says that the follower will patent A when he has the chance to do so, since patenting it yields $\pi_{\mathrm{FW}}$ to him whereas not patenting it yields only $\pi_{\mathrm{NP}}\left(<\pi_{\mathrm{FW}}\right)$. This is important enough to be presented in:

Proposition 1: If the follower catches up to the leader with his own discovery of invention A, he patents it. This yields the expected profits $\pi_{\mathrm{LU}}$ to the leader and $\pi_{\mathrm{FW}}$ to the follower, where $\pi_{\mathrm{LU}}$ and $\pi_{\mathrm{FW}}$ are defined in (3) and (4), respectively.

We now move back to the leader's first node in figure 1. Patenting A, the leader faces the expected profit $\pi_{\mathrm{PH}}$ as the patent holder. Not patenting A, she starts the asymmetric race, where she faces the hazard rate $\lambda$ while the follower faces the hazard rate $g(y)$, with y denoting his $R \& D$ investment in this race. Thus, the leader's expected profit at this node partially depends on g(y). 
To compute its equilibrium value, observe that winning this asymmetric race yields the expected profit $\pi_{\mathrm{FW}}$ to the follower by Proposition 1 whereas losing it he gets nothing. Thus, we can write the follower's expected profit from the asymmetric race as in

$$
\frac{g(y) \pi_{\mathrm{FW}}-y}{r+\lambda+g(y)}
$$

The follower chooses y to maximize this profit. Let $\mathrm{y}^{*}$ denote the optimal $\mathrm{y}$, and write the corresponding follower's profit as;

$$
\varphi_{\mathrm{F}}^{*}=\frac{g(y *) \pi_{\mathrm{FW}}-y *}{r+\lambda+g(y *)} .
$$

Given $y^{*}$, the leader's expected profit can be computed. If she wins the asymmetric race she holds the patents on both inventions worth V. If she loses it, the leader's profit is $\pi_{\mathrm{LU}}$ by Proposition 1. Therefore, the profit to the leader, if she does not patent A, is given by

$$
\varphi_{\mathrm{L}}^{*}=\frac{\lambda V+g(y *) \pi_{\mathrm{LU}}}{r+\lambda+g(y *)}
$$

The next proposition is immediate.

Proposition 2: In a non-harmonized world, the leader patents invention A if and only if $\pi_{\mathrm{PH}} \geq \varphi_{\mathrm{L}} * 12$

We are now in a position to specify the expected profits $\Pi_{L}$ and $\Pi_{F}$ in (1). If the leader patents A, by Proposition 2 we set $\Pi_{\mathrm{L}}=\pi_{\mathrm{PH}}$ and $\Pi_{\mathrm{F}}=\pi_{\mathrm{NP}}$. Substituting these profits into the first-order condition (1), we can solve for the symmetric equilibrium level of R\&D investment, which we denote by $\mathrm{x}_{\mathrm{P}}{ }^{*}$, where the subscript $\mathrm{P}$ is a mnemonic for "patenting”.

On the other hand, if the leader does not patent $\mathrm{A}$ at her first node in figure 1 , the preceding analysis puts $\Pi_{\mathrm{L}}=\varphi_{\mathrm{L}}{ }^{*}$ and $\Pi_{\mathrm{F}}=\varphi_{\mathrm{F}}{ }^{*}$. Putting these into (1), we obtain the equilibrium

\footnotetext{
${ }^{12}$ Figure 3 illustrates the parameter condition in our numerical example.
} 
R\&D investment, which we denote by $\mathrm{x}_{\mathrm{N}}{ }^{*}$, where the subscript $\mathrm{N}$ stands for "not patenting". In the next section we examine the effect on R\&D investments as the U.S. switches from FTI to FTF.

\section{A harmonized world}

This section considers a world in which both countries use a FTF rule. The analysis closely follows that of the previous section, so our description is relatively brief and relies mostly on figure 2, analogous to figure 1.

Begin at the leader's second node. If she chooses not to patent A, a race begins towards B and a winner gets patent on A and B in both countries, since the leader no longer holds priority of invention A in a harmonized world under FTF. Thus, each agents faces the identical expected profit of:

$$
\pi_{\mathrm{N}} \equiv \lambda \mathrm{V} /(\mathrm{r}+2 \lambda)
$$

On the other hand, patenting A, the leader can secure the patent holder's profit $\pi_{\mathrm{PH}}$ defined in the previous section. Since $\pi_{\mathrm{PH}}>\pi_{\mathrm{N}}$, the leader patents A. Now, move back to the follower's node in figure 2. If he does not patent $\mathrm{A}$, his expected profit will be $\pi_{\mathrm{NP}}$ as the leader will patent it. On the other hand, if he gets patents on $\mathrm{A}$ in both countries, he secures $\alpha \mathrm{V}$. Further, if he wins the race towards B, he can pick up the additional profit from the patent on B. Thus, a follower's expected profit is:

$$
\pi_{\mathrm{PH}}=\frac{\lambda V(1+\alpha)}{r+2 \lambda}
$$

Since $\pi_{\mathrm{PH}}>\pi_{\mathrm{NP}}$, the follower patents A, in which case the leader's expected profit is reduced to $\pi_{\mathrm{NP}}$. The following thus contrasts with proposition 1 .

Proposition 3: If the follower catches up to the leader with his own discovery of invention A, he patents it. This yields the expected profits $\pi_{\mathrm{NP}}$ to the leader and $\pi_{\mathrm{PH}}$. 
Note that this proposition differs from proposition 1 only in the evaluations of profits. It can be shown that $\pi_{\mathrm{PH}}>\pi_{\mathrm{FW}}$ and $\pi_{\mathrm{NP}}<\pi_{\mathrm{LU}}$, so if play reaches the follower's node in figure 2 , international patent law harmonization raises the profit to the follower and reduces the profit to the leader.

We next turn to the leader's decision at her first node. If she patents $\mathrm{A}$, she faces the expected profit $\pi_{\mathrm{PH}}$ as in a non-harmonized world. If she does not patent $\mathrm{A}$, she launches an asymmetric race, where her expected profit depends on the follower's hazard rate g(y) as before. To compute g(y), note that the follower, if he wins the asymmetric race, faces the expected profit $\pi_{\mathrm{PH}}$ by proposition 3 , so the follower's expected profit is written as;

$$
\frac{g(y) \pi_{\mathrm{PH}}-y}{r+\lambda+g(y)}
$$

Let $\mathrm{y}^{* *}$ maximize this expression, and write the corresponding maximal profit as;

$$
\varphi_{\mathrm{F}}^{* *}=\frac{g(y * *) \pi_{\mathrm{PH}}-y * *}{r+\lambda+g(y * *)} \text {. }
$$

Now we can compute the leader's equilibrium profit from the asymmetric race. If she wins this race, she holds all the patents valued V. If the follower wins the race, then the leader's profit is $\pi_{\mathrm{NP}}$ by proposition 3. Given the follower's equilibrium hazard rate $g\left(\mathrm{y}^{* *}\right)$, the leader's profit is expressed as;

$$
\varphi_{\mathrm{L}}^{* *}=\frac{\lambda V+g(y * *) \pi_{\mathrm{NP}}}{r+\lambda+g(y * *)}
$$

Proposition 4: In a harmonized world under FTF, the leader patents invention A (at her first node) if and only if $\pi_{\mathrm{PH}}>\varphi_{\mathrm{L}}^{* *}$.

We can now determine the equilibrium levels of $R \& D$ investment in the race for invention A in a harmonized world. Proposition 4 puts $\Pi_{\mathrm{L}}=\pi_{\mathrm{PH}}$ and $\Pi_{\mathrm{F}}=\pi_{\mathrm{NP}}$ if the leader patents A. Since these profits are the same as in a non-harmonized world, the equilibrium R\&D 
investment is also identical as in the previous section, that is, $\mathrm{x}_{\mathrm{P}}{ }^{* *}=\mathrm{x}_{\mathrm{P}}{ }^{*}$. We thus conclude that, if the leader patents $\mathrm{A}$ in both worlds, patent law harmonization has no effect on $\mathrm{R} \& \mathrm{D}$ investments.

Suppose, on the other hand, that the leader does not patent A in a harmonized world. Then proposition 4 puts $\Pi_{\mathrm{L}}=\varphi_{\mathrm{L}}{ }^{* *}$ and $\Pi_{\mathrm{F}}=\varphi_{\mathrm{F}}{ }^{* *}$. Substituting them into (1), we obtain the symmetric equilibrium $R \& D$ investments, which we denote by $x_{N}{ }^{* *}$.

\section{The R\&D effect of international patent law harmonization}

In this section, we compare $\mathrm{x}_{\mathrm{N}}{ }^{*}$ and $\mathrm{x}_{\mathrm{N}}{ }^{* *}$. We first prove, in appendix $\mathrm{A}$, the following key results.

Proposition 5: (i) $\varphi_{\mathrm{L}}^{* *}<\varphi_{\mathrm{L}}^{*}$ and (ii) $\varphi_{\mathrm{F}}^{* *}>\varphi_{\mathrm{F}}^{*}$.

The first part of the proposition says that, when the leader does not patent A, harmonization lowers her expected profit, whereas the second part states that harmonization raises the follower's profit. This can be explained intuitively as follows. Hold the follower's investment y in R\&D for a moment. Then, if the leader does not get a patent on $\mathrm{A}$, her hold on invention $\mathrm{A}$ is more tenuous in a harmonized world, where the follower can get patents on A in both countries when he catches up to her, than in a non-harmonized world, where she has priority of invention in the U.S. Thus the leader's expected profit is smaller in a harmonized world. Similarly, if the follower catches up with his own discovery of $\mathrm{A}$, he can get patents on $\mathrm{A}$ in both countries in a harmonized world, but only in the rest of the world in a non-harmonized world. Thus, the follower's profit is greater in a harmonized world than in a non-harmonized world.

In the equilibrium analysis, the follower chooses $y$, which strengthens the above argument. To see this, note that since harmonization raises the expected profit to the follower, the 
follower invests more in R\&D in a harmonized world. The resultant increase in the hazard rate g(y) further increases the follower's expected profit while decreasing the leader's expected profit.

The first part of proposition 5 leads to the following corollary.

Corollary 1: $\varphi_{\mathrm{L}}^{*}<\pi_{\mathrm{PH}}$ implies $\varphi_{\mathrm{L}}^{* *}<\pi_{\mathrm{PH}}$; that is, if the leader patents $\mathrm{A}$ in a nonharmonized world, she does so in a harmonized world as well.

Thanks to corollary 1 we need consider only the following three mutually exclusive possibilities facing the leader at her first node.

$$
\begin{aligned}
& \text { Case 1: } \pi_{\mathrm{PH}}<\varphi_{\mathrm{L}}^{* *}<\varphi_{\mathrm{L}}{ }^{*} \\
& \text { Case 2: } \varphi_{\mathrm{L}}{ }^{* *}<\pi_{\mathrm{PH}}<\varphi_{\mathrm{L}}{ }^{*} \\
& \text { Case 3: } \varphi_{\mathrm{L}}{ }^{* *}<\varphi_{\mathrm{L}}{ }^{*}<\pi_{\mathrm{PH}}
\end{aligned}
$$

We consider each case separately.

\section{Case 1: $\pi_{\mathrm{PH}}<\varphi_{\mathrm{L}}^{* *}<\varphi_{\mathrm{L}} *$.}

In this case the leader does not patent A before or after harmonization. Therefore, the expected profits are $\left(\Pi_{\mathrm{L}}, \Pi_{\mathrm{F}}\right)=\left(\varphi_{\mathrm{L}}{ }^{*}, \varphi_{\mathrm{F}}{ }^{*}\right)$ for a non-harmonized world and $\left(\Pi_{\mathrm{L}}, \Pi_{\mathrm{F}}\right)=\left(\varphi_{\mathrm{L}}{ }^{* *}, \varphi_{\mathrm{F}}{ }^{* *}\right)$ for a harmonized world. Then, proposition 5 implies that harmonization decreases the expected profit to the leader and increases that to the follower. Then, lemma 1 implies $x_{N}{ }^{* *}<x_{N}{ }^{*}$; that is, harmonization reduces investments in $\mathrm{R} \& \mathrm{D}$ for invention $\mathrm{A}$. Intuitively, harmonization makes success less rewarding and failure more tolerable, thereby softening $R \& D$ competition for the leadership.

\section{Case 2: $\varphi_{\mathrm{L}}^{* *}<\pi_{\mathrm{PH}}<\varphi_{\mathrm{L}}^{*}$.}

In this case, harmonization induces the leader to change her decision from not patenting to patenting invention $A$. This puts $\left(\Pi_{L}, \Pi_{F}\right)=\left(\varphi_{L}^{*}, \varphi_{F}^{*}\right)$ in a non-harmonized world and $\left(\Pi_{L}, \Pi_{F}\right)$ 
$=\left(\pi_{\mathrm{PH}}, \pi_{\mathrm{NP}}\right)$ in a harmonized world. Since $\pi_{\mathrm{PH}}<\varphi_{\mathrm{L}}{ }^{*}$, harmonization reduces the leader's profit. As for the leader-follower profit difference, we show in appendix B that

$$
\Delta \equiv\left(\varphi_{\mathrm{L}}^{*}-\varphi_{\mathrm{F}}^{*}\right)-\left(\pi_{\mathrm{PH}}-\pi_{\mathrm{NP}}\right)>0,
$$

i. e., harmonization narrows the leader-follower profit difference as well. Then, we appeal to lemma 1 to conclude that $\mathrm{x}_{\mathrm{P}}{ }^{* *}<\mathrm{x}_{\mathrm{N}}{ }^{*}$; again harmonization decreases $\mathrm{R} \& \mathrm{D}$ investments for invention A.

Case 3: $\varphi_{\mathrm{L}}^{* *}<\varphi_{\mathrm{L}}^{*}<\pi_{\mathrm{PH}}$.

In this final case, a leader patents A with or without harmonization. Accordingly, the symmetric $R \& D$ investments are the same in both scenarios, $x_{\mathrm{P}}{ }^{*}=\mathrm{x}_{\mathrm{P}}{ }^{* *}$. Therefore, harmonization has no effect on invention.

The next proposition summarizes the key findings.

\section{Proposition 6:}

(A) When $\pi_{\mathrm{PH}}<\varphi_{\mathrm{L}}{ }^{*}$ international harmonization delays discovery of invention $\mathrm{A}\left(\mathrm{x}_{\mathrm{N}}{ }^{*}>\right.$ $\left.\mathrm{x}_{\mathrm{N}}^{* *}\right)$.

(B) When $\varphi_{\mathrm{L}}^{*} \leq \pi_{\mathrm{PH}}$, harmonization has no effect.

It is possible to further characterize the condition $\pi_{\mathrm{PH}}<\varphi_{\mathrm{L}}{ }^{*}$. Substituting for $\varphi_{\mathrm{L}}{ }^{*}$ from (6) and rearranging, we can rewrite this inequality as;

$$
\left[(\mathrm{r}+\lambda) \pi_{\mathrm{PH}}-\lambda \mathrm{V}\right]+\mathrm{g}\left(\mathrm{y}^{*}\right)\left(\pi_{\mathrm{PH}}-\pi_{\mathrm{LU}}\right)<0 .
$$

Using $\pi_{\mathrm{PH}}$ from (2) and $\pi_{\mathrm{LU}}$ from (4), we can show that the second term is positive since;

$$
\pi_{\mathrm{PH}}-\pi_{\mathrm{LU}}=2 \alpha \mathrm{V}_{\mathrm{w}} /(\mathrm{r}+2 \lambda)>0
$$

so for (9) to hold we must have that $(\mathrm{r}+\lambda) \pi_{\mathrm{PH}}-\lambda \mathrm{V}<0$. This condition in turn can be expressed as 


$$
(r+\lambda)(1+\alpha)-(r+2 \lambda)=\alpha r-\beta \lambda<0
$$

This last inequality is more likely to hold if it is easier to discover invention B (high $\lambda$ ) or if B has higher commercial value (large $\beta$, small $\alpha$ ).

We also can characterize the condition in terms of market size. Define $\mu \equiv V_{\mathrm{u}} / \mathrm{V}$; i. e., let $\mu$ denote the fraction of total value that accrues from the U.S. market. It can be checked that an increase in $\mu$ reduces the difference $\pi_{\mathrm{PH}}-\pi_{\mathrm{LU}}$ in (10). Higher $\mu$ also reduces $\pi_{\mathrm{FW}}$ given in (3), thereby decreasing $\mathrm{g}\left(\mathrm{y}^{*}\right)$ via (5). Thus, an increase in the U.S. share $\mu$ reduces the value of the third term in (10), making (10) more likely to hold. That is, if the product yields greater value in the U.S. market, the necessary condition for delayed invention of A is more likely to be satisfied.

Delayed discovery of invention A can also delay that of invention B. To clarify such possibilities, let us compute the mean time needed for discovery of both inventions, which we denote by $\mathrm{E}(\tau)$. This is computed by the sum of times needed to discover each invention under several scenarios as follows. Agents first compete for invention A, which has the mean discovery time $1 /(2 g(x))$. If invention $A$ is not patented, the asymmetric race ensues with discovery of $A$. This phase takes the mean time $1 /(\mathrm{g}(\mathrm{y})+\lambda)$ and ends either with discovery of B by the leader or discovery of A by the follower. In the former case the game ends with the leader getting all the patents. In the latter, which occurs with probability $\mathrm{g}\left(\mathrm{y}^{*}\right) /\left(\mathrm{g}\left(\mathrm{y}^{*}\right)+\lambda\right)$, the symmetric race towards

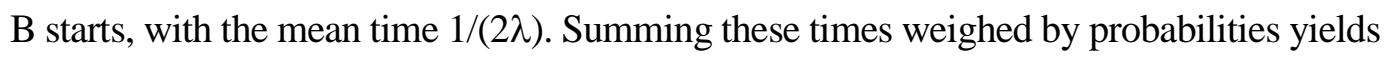

$$
\mathrm{E}(\tau)=1 /(2 \mathrm{~g}(\mathrm{x}))+1 /(\mathrm{g}(\mathrm{y})+\lambda)+\mathrm{g}(\mathrm{y}) /[2 \lambda(\mathrm{g}(\mathrm{y})+\lambda)],^{13}
$$

which simplifies to

$$
\mathrm{E}(\tau)=1 /(2 \mathrm{~g}(\mathrm{x}))+1 /(2 \lambda)+1 /[2(\mathrm{~g}(\mathrm{y})+\lambda)]
$$

On the other hand, if invention $\mathrm{A}$ is patented, discovery of $\mathrm{A}$ is followed immediately by the symmetric race toward B so the mean time needed to discover both inventions is

\footnotetext{
${ }^{13}$ Details are available on request.
} 


$$
\mathrm{E}(\tau)=1 /(2 \mathrm{~g}(\mathrm{x}))+1 /(2 \lambda)
$$

In case 1 , invention $\mathrm{A}$ is not patented so the mean time for discovery of both invention in a non-harmonized world is

$$
\mathrm{E}\left(\tau^{*}\right)=1 /\left(2 \mathrm{~g}\left(\mathrm{x}_{\mathrm{N}}^{*}\right)\right)+1 /(2 \lambda)+1 /\left[2\left(\mathrm{~g}\left(\mathrm{y}^{*}\right)+\lambda\right)\right]
$$

whereas that for a harmonized world is

$$
\mathrm{E}\left(\tau^{* *}\right)=1 /\left(2 \mathrm{~g}\left(\mathrm{x}_{\mathrm{N}}^{* *}\right)\right)+1 /(2 \lambda)+1 /\left[2\left(\mathrm{~g}\left(\mathrm{y}^{* *}\right)+\lambda\right)\right] .
$$

To compare these two expression, proposition 6 says that $\mathrm{x}_{\mathrm{N}}{ }^{*}>\mathrm{x}_{\mathrm{N}}{ }^{* *}$, so the first term on the right of (11) is less than that of (12). However, $y^{*}<y^{* *}$, that is, the follower invests more in the asymmetric race in a harmonized world because winning gives him $\pi_{\mathrm{PH}}$ instead of $\pi_{\mathrm{FW}}$. This makes the third term on the right of (11) greater than that of (12). Thus, it is not clear whether we have $\mathrm{E}\left(\tau^{*}\right)>\mathrm{E}\left(\tau^{* *}\right)$ or not.

In case 2, as invention gets patented, the mean time is

$$
\mathrm{E}(\tau * *)=1 /\left(2 \mathrm{~g}\left(\mathrm{x}_{\mathrm{P}}{ }^{* *}\right)\right)+1 /(2 \lambda) .
$$

The difference is

$$
\mathrm{E}\left(\tau^{*}\right)-\mathrm{E}\left(\tau^{* *}\right)=1 / \mathrm{g}\left(\mathrm{x}_{\mathrm{N}}^{*}\right)-1 / \mathrm{g}\left(\mathrm{x}_{\mathrm{P}}^{* *}\right)+1 /\left(\mathrm{g}\left(\mathrm{y}^{*}\right)+\lambda\right) .
$$

The first two terms sum to a negative number, measuring a delay in discovery of invention A due to harmonization, whereas the third term measures the expected duration of the asymmetric race that occurs only in a non-harmonized world. Again, it is in general difficult to sign the above expression unambiguously. In the next section we specify functional form for the hazard rate function and perform simulation exercises to determine the effect on mean time needed to discover both inventions. 


\section{Numerical analysis}

This section numerically evaluates the effect of international harmonization of patentissuing rules. Assume the following hazard rate function:

$$
\mathrm{g}(\mathrm{x}) \equiv(2 \mathrm{x})^{0.5}
$$

which satisfies the Inada conditions. Substituting it into the first-order condition (1) yields, after routine operations, the equilibrium $R \& D$ investment $\mathrm{x}$. The corresponding hazard rate is given by:

$$
g(x)=\left\{(\Theta-r)+\left[(\Theta-r)^{2}+6 r \Pi_{L}\right]^{0.5}\right\} / 3
$$

as a function of $\Pi_{\mathrm{L}}$ and $\Theta \equiv \Pi_{\mathrm{L}}-\Pi_{\mathrm{F} \cdot}{ }^{14}$

The equilibrium level $\mathrm{y}^{*}$ of $\mathrm{R} \& \mathrm{D}$ investment towards $\mathrm{A}$ by the follower in an asymmetric race can be computed using (5). In the equilibrium without harmonization, the hazard rate for the follower is given by:

$$
\mathrm{g}\left(\mathrm{y}^{*}\right)=\left\{(\mathrm{r}+\lambda)+\left[(\mathrm{r}+\lambda)^{2}+2 \pi_{\mathrm{FW}}(\mathrm{r}+\lambda)\right]^{0.5}\right\}
$$

An analogous procedure applied to a harmonized world yields $\mathrm{y}^{* *}$, which maximizes (8). The associated hazard rate is given by;

$$
g\left(y^{* *}\right)=\left\{(r+\lambda)+\left[(r+\lambda)^{2}+2 \pi_{P H}(r+\lambda)\right]^{0.5}\right\} .
$$

Substituting these equilibrium hazard rates into (6) and (8), we can compute $\varphi_{\mathrm{L}}{ }^{*}$ and $\varphi_{\mathrm{L}}{ }^{* *}$.

We use these equations to draw figures 3 through 6 below for the parameter values $\mathrm{V}=$ $30, \alpha=0.15$, and $r=0.8 .{ }^{15}$ Figure 3 shows the conditions under which the three cases emerge at various values of $\lambda$ and the relative size of the U.S. market $\mu$. According to figure 3 , when $\lambda$ is greater than about 17.5 , i.e., it is sufficiently easy to discover invention $\mathrm{B}$, then case 1 occurs, independently of the relative size of the U.S. market. When both $\lambda$ and $\mu$ are small, case 3 occurs

\footnotetext{
${ }^{14}$ Derivations are available from the authors upon request.

${ }^{15}$ Parameter values are chosen so that 3D surfaces are easy to see. Our results are robust for all the relevant parameter values we considered. Details of the numerical analysis can be obtained from the authors (c.f. http://www.econ.hokudai.ac.jp/ ohno/Patent_Num.html).
} 
so the leader always patents A irrespective of patent law being harmonized. Thus, we see that the leader changes her patenting strategy only when $\lambda$ is in the intermediate range and $\mu$ is relatively large.

Building on figure 3, figure 4 plots the equilibrium R\&D levels for invention A on the vertical axis (the axes for $\lambda$ and $\mu$ are interchanged from the previous figures for facile presentation). For each point in figure 4, the green surface represents the R\&D levels without harmonization and the purple surface shows those after harmonization. A comparison confirms our result that harmonization decreases $R \& D$ investments for invention A except in case 3, where harmonization has no impact.

Figure 5 shows the mean discovery dates of both inventions, with the purple surface representing the dates in a harmonized world. The two surfaces are identical in the regions corresponding to case 3, as expected. What is surprising is that in the other regions the purple surface lies above the green surface, implying that in cases 1 and 2 harmonization delays discovery of both inventions.

Figure 6 measures the expected profits to an agent. As the green surface lies above the purple one except in case 3, it is found that harmonization decreases the overall expected profits to each firm, evaluated at $\mathrm{t}=0$.

The analysis of this section allows us to make inferences about the welfare implications of patent law harmonization. Clearly, in case 3 there will be no welfare change. In cases 1 and 2, by contrast, we have found that harmonization delays discovery of both inventions and also decreases the expected profit to each agent. It follows that world welfare clearly declines as a result of harmonization. 


\section{Concluding remarks}

With the passage of the American Invents Act of 2011, the U.S. has finally decided to discard the FTI feature of its patent law in favor of the FTF rule, the international norm. It is the objective of this paper to study the effect and ramifications of this controversial policy change in a two-country model of R\&D competition for two sequential inventions. Our main conclusion is that patent law harmonization can undermine innovations and can negatively impact world welfare.

Further analysis shows that such a possibility increases if basic research is difficult to discover but its commercialization is relatively easy, or if inventions generate greater value in the U.S. relative to the rest of the world. Thus, our model implies that inventive activities may slow down in such industries as pharmaceutical and semiconductor as a result of the America Invents Act of 2011.

The America Invests Act is expected to come into effect on March 16, 2013. The recent empirical work of Lo and Sutthiphisal (2009), studying the Canadian episode, finds that the similar rule change instituted in Canada resulted in less investment in R\&D in that country. We hope that our work will stimulate similar empirical work in the near future. 


\section{Appendices}

Appendix A. Proof of Proposition 5: First we compare a follower's profits:

$$
\varphi_{\mathrm{F}}^{*}=\left(\mathrm{g}\left(\mathrm{y}^{*}\right) \pi_{\mathrm{FW}}-\mathrm{y}^{*}\right) /\left(\mathrm{r}+\lambda+\mathrm{g}\left(\mathrm{y}^{*}\right)\right)
$$

for a non-harmonized world, and

$$
\varphi_{\mathrm{F}}^{* *}=\left(\mathrm{g}\left(\mathrm{y}^{* *}\right) \pi_{\mathrm{PH}}-\mathrm{y}^{* *}\right) /\left(\mathrm{r}+\lambda+\mathrm{g}\left(\mathrm{y}^{* *}\right)\right)
$$

for a harmonized world. $\pi_{\mathrm{PH}}>\pi_{\mathrm{FW}}$ implies $\mathrm{y}^{* *}>\mathrm{y}^{*}$. Then it is immediately that $\varphi_{\mathrm{F}}^{* *}>\varphi_{\mathrm{F}}^{*}$. We next compare a leader's profits

$$
\varphi_{\mathrm{L}}^{*}=\left[\lambda \mathrm{V}+\mathrm{g}\left(\mathrm{y}^{*}\right) \pi_{\mathrm{LU}}\right] /\left(\mathrm{r}+\lambda+\mathrm{g}\left(\mathrm{y}^{*}\right)\right)
$$

for a non-harmonized world and

$$
\varphi_{\mathrm{L}}^{* *}=\left[\lambda \mathrm{V}+\mathrm{g}\left(\mathrm{y}^{* *}\right) \pi_{\mathrm{NP}}\right] /\left(\mathrm{r}+\lambda+\mathrm{g}\left(\mathrm{y}^{* *}\right)\right)
$$

for a harmonized world. Define the function $\xi(y)=\left[\lambda V+g(y) \pi_{N P}\right] /(r+\lambda+g(y))$.Then,

$$
\xi^{\prime}(y)=g^{\prime}(y)\left[(r+\lambda) \pi_{N P}-\lambda V\right] /(r+\lambda+g(y))^{2} .
$$

Substituting for $\pi_{\mathrm{NP}}$, we rewrite the expression in brackets on the right as

$$
(\mathrm{r}+\lambda) \pi_{\mathrm{NP}}-\lambda \mathrm{V}=(\mathrm{r}+\lambda) \lambda \beta \mathrm{V} /(\mathrm{r}+2 \lambda)-\lambda \mathrm{V}<0
$$

Thus, $\mathrm{m}^{\prime}(\mathrm{y})<0$. Since $\mathrm{y}^{* *}>\mathrm{y}^{*}$,

$$
\begin{aligned}
\varphi_{\mathrm{L}}^{* *}= & {\left[\lambda \mathrm{V}+\mathrm{g}\left(\mathrm{y}^{* *}\right) \pi_{\mathrm{NP}}\right] /\left(\mathrm{r}+\lambda+\mathrm{g}\left(\mathrm{y}^{* *}\right)\right) } \\
& <\left[\lambda \mathrm{V}+\mathrm{g}\left(\mathrm{y}^{*}\right) \pi_{\mathrm{NP}}\right] /\left(\mathrm{r}+\lambda+\mathrm{g}\left(\mathrm{y}^{*}\right)\right) \\
& <\left[\lambda \mathrm{V}+\mathrm{g}\left(\mathrm{y}^{*}\right) \pi_{\mathrm{LU}}\right] /\left(\mathrm{r}+\lambda+\mathrm{g}\left(\mathrm{y}^{*}\right)\right)=\varphi_{\mathrm{L}}^{* *},
\end{aligned}
$$

where the final inequality follows because $\pi_{\mathrm{LU}}>\pi_{\mathrm{NP}}$.

\section{Appendix B. Proof that harmonization narrows the leader-follower profit differential in Case 2}

Since $\varphi_{\mathrm{L}}{ }^{*}>\pi_{\mathrm{PH}}$, to show $\Delta>0$ it suffices to show that

$$
\pi_{\mathrm{NP}}-\varphi_{\mathrm{F}}^{*}=\pi_{\mathrm{NP}}-\left(\mathrm{g}\left(\mathrm{y}^{*}\right) \pi_{\mathrm{FW}}-\mathrm{y}^{*}\right) /\left(\mathrm{r}+\lambda+\mathrm{g}\left(\mathrm{y}^{*}\right)\right)>0
$$

This is equivalent to 


$$
\mathrm{D} \equiv \mathrm{y}^{*}+(\mathrm{r}+\lambda) \pi_{\mathrm{NP}}+\mathrm{g}\left(\mathrm{y}^{*}\right)\left(\pi_{\mathrm{NP}}-\pi_{\mathrm{FW}}\right)>0 .
$$

We thus need only to show $\mathrm{D}>0$. First, by the definitions $\varphi_{\mathrm{L}}{ }^{*}>\pi_{\mathrm{PH}}$ implies that

$$
\varphi_{\mathrm{L}}^{*}-\pi_{\mathrm{PH}}=\left(\lambda \mathrm{V}+\mathrm{g}\left(\mathrm{y}^{*}\right) \pi_{\mathrm{LU}}\right) /\left(\mathrm{r}+\lambda+\mathrm{g}\left(\mathrm{y}^{*}\right)\right)-\pi_{\mathrm{PH}}>0 \text {, }
$$

which simplifies to

$$
\mathrm{g}\left(\mathrm{y}^{*}\right)\left(\pi_{\mathrm{LU}}-\pi_{\mathrm{PH}}\right)>(\mathrm{r}+\lambda) \pi_{\mathrm{PH}}-\lambda \mathrm{V}
$$

Next, it is easy to verify that

$$
\pi_{\mathrm{NP}}+\pi_{\mathrm{PH}}=\pi_{\mathrm{LU}}+\pi_{\mathrm{FW}}=2 \lambda \mathrm{V} /(\mathrm{r}+2 \lambda)
$$

Hence,

$$
\pi_{\mathrm{NP}}-\pi_{\mathrm{FW}}=\pi_{\mathrm{LU}}-\pi_{\mathrm{PH}}
$$

Substituting, we can rewrite the condition in (B1) as

$$
\mathrm{g}\left(\mathrm{y}^{*}\right)\left(\pi_{\mathrm{NP}}-\pi_{\mathrm{FW}}\right)>(\mathrm{r}+\lambda) \pi_{\mathrm{PH}}-\lambda \mathrm{V} .
$$

Substituting this into the expression in D, we can show

$$
\mathrm{D}>\mathrm{y}^{*}+(\mathrm{r}+\lambda)\left(\pi_{\mathrm{NP}}+\pi_{\mathrm{PH}}\right)-\lambda \mathrm{V} .
$$

But

$$
(\mathrm{r}+\lambda)\left(\pi_{\mathrm{NP}}+\pi_{\mathrm{PH}}\right)-\lambda \mathrm{V}=\lambda \mathrm{V}[2(\mathrm{r}+\lambda) /(\mathrm{r}+2 \lambda)-1]>0
$$

Therefore, $\mathrm{D}>0$, and $\Delta>0$. 


\section{References}

Chang, H. F, 1995, Patent scope, antitrust and cumulative innovation, RAND Journal of Economics 26, 34-57.

Cohen, L. R., and Ishii, J., 2005, Competition, innovation, and racing for priority at the U.S. Trademark and Patent Office, AER-Brookings Joint Center for Regulatory Studies Working Paper 05-22.

Hart, Herbert D., III, 2007. An interference: what, when, and how much does it cost? The American Bar Association Section of Intellectual Property Law, available as a PDF file at hppt://www.mhmlaw.com

Kao, T., 2009, Strategic licensing and sequential innovations, The Manchester School 77, 521551.

Lee, Tom and Louis L. Wild, 1980, Market structure and innovation: a reformation, Quarterly Journal of Economics 94, 429-436.

Lerner, Josh, 2003, The patent system and competition, a statement to the Federal Trade Commission/Department of Justice hearings on competition and intellectual property law and policy in the knowledge-based economy, www.ftc.gov/opp/intellect/lernerjosh.pdf

Lo, Shih-tse and Dhanoos Sutthiphisal, 2009. Does it matter who has the right to patent firstto-invent or first-to-file? Lessons from Canada, National Bureau of Economic Research Working Paper 14926

Moser, Peter, 2005, How do Patent Laws Influence Innovation? Evidence from NineteenthCentury World’s Fairs, American Economic Review 95, 1214-1236.

Scotchmer Suzanne, and Jerry Green, 1990. Novelty and discloser in patent law, RAND Journal of Economics 21, 131-146.

Standard \& Poor’s, Industry Surveys - Healthcare: Pharmaceuticals. June 2, 2011. 
Figure 1: A World Without Patent Harmonization

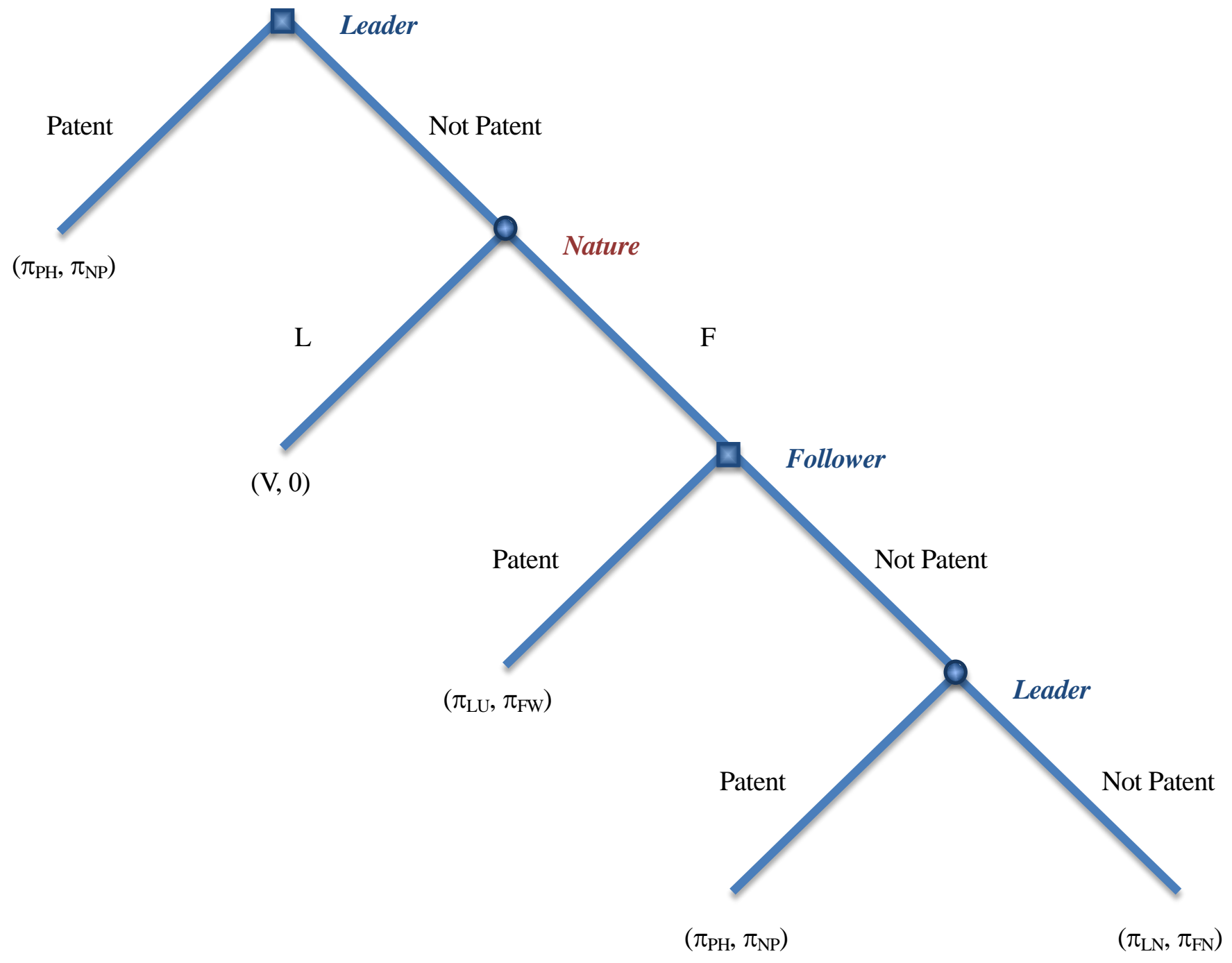


Figure 2: A Harmonized World

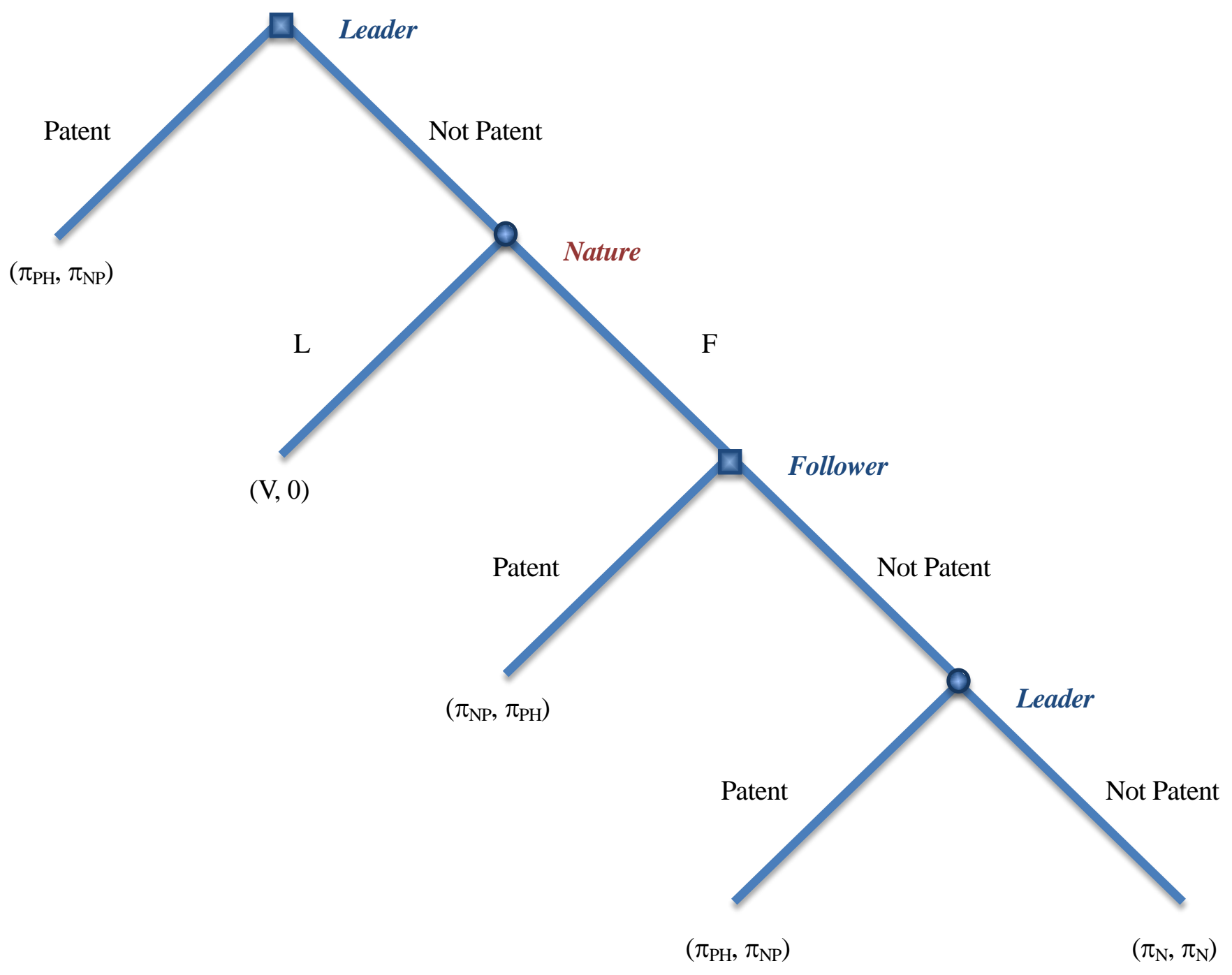


Figure 3: Patent or No Patent - 3 Cases

$\lambda$

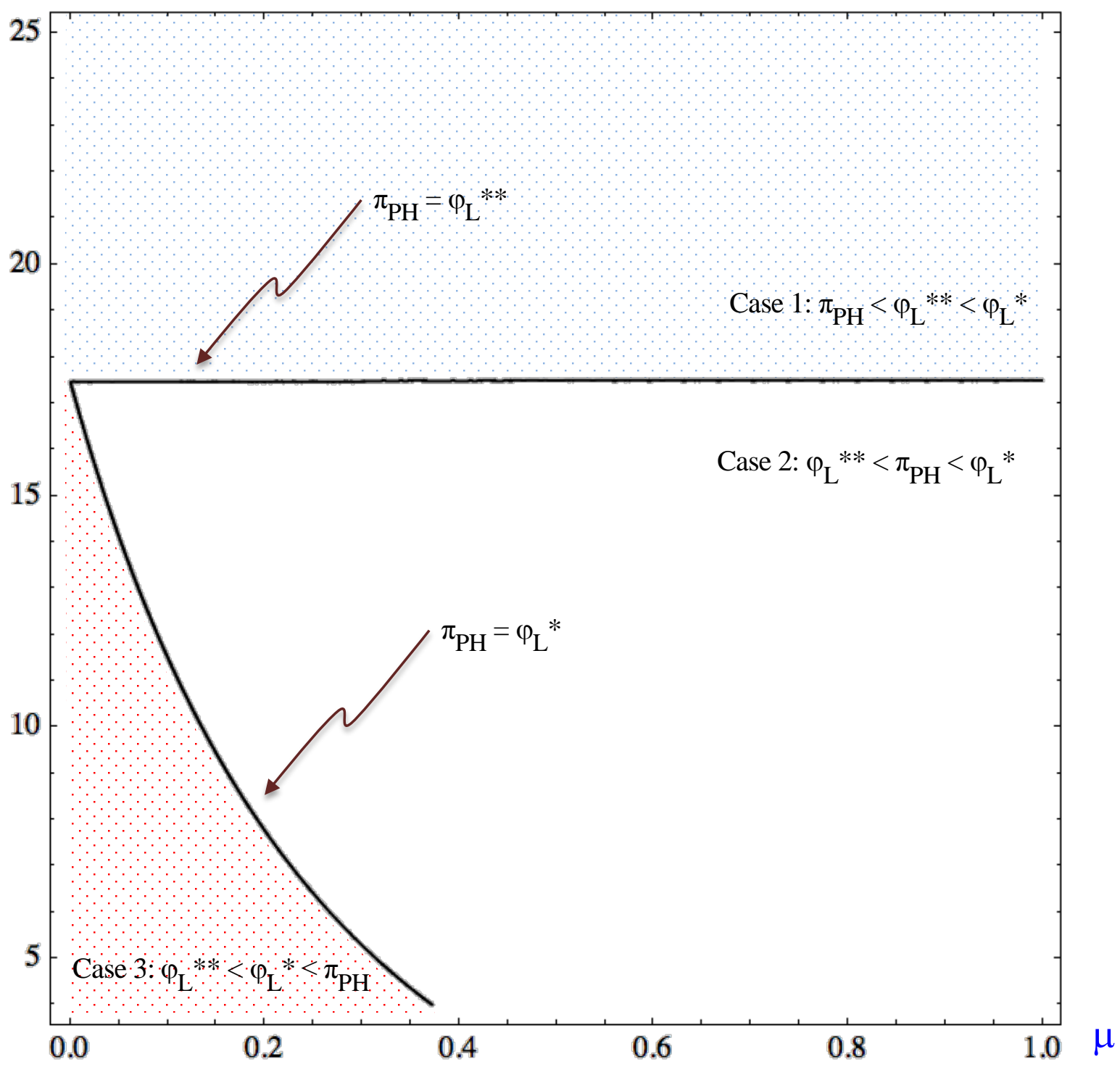


Figure 4: R\&D investments - Harmonization reduces R\&D efforts

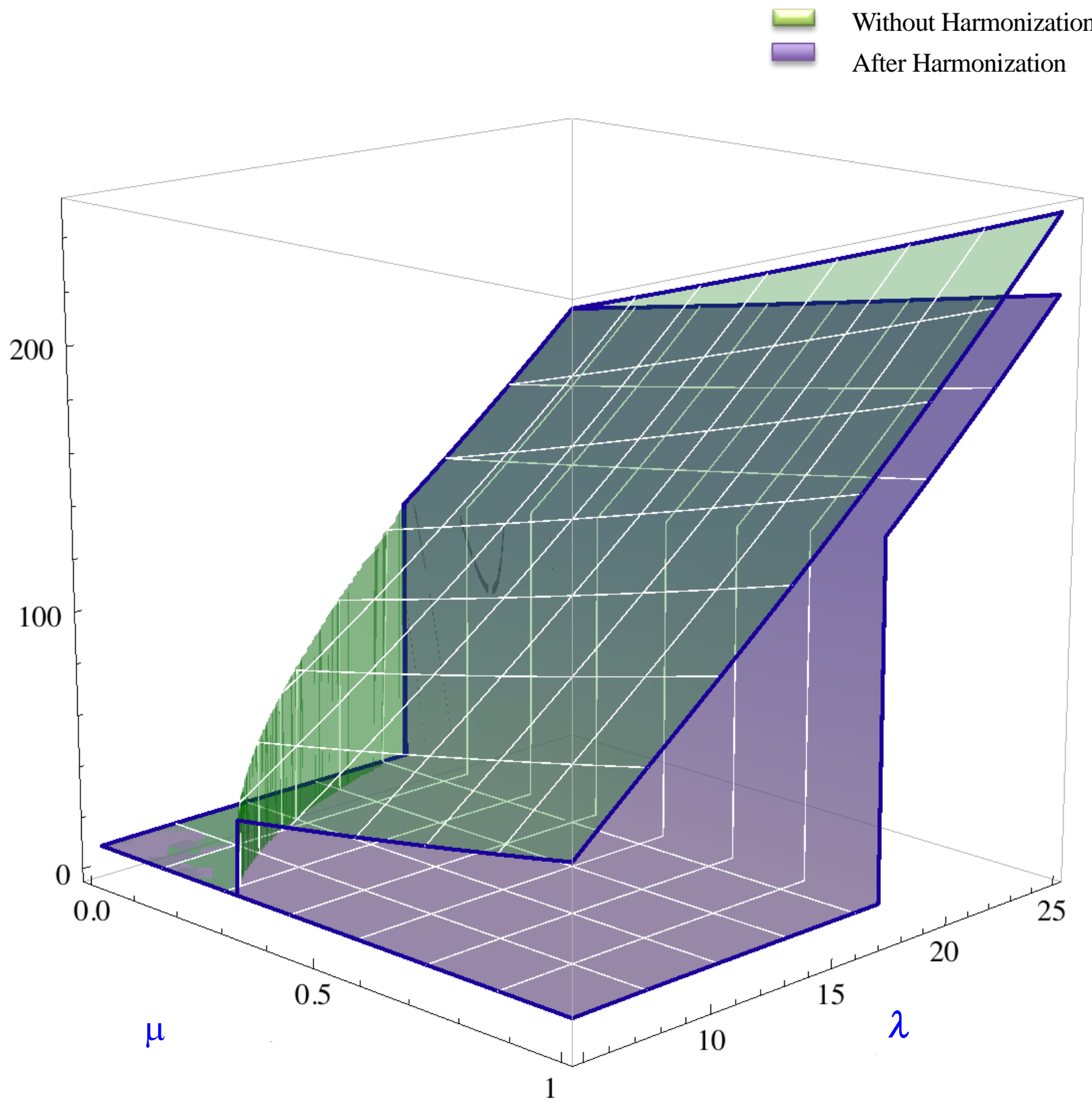


Figure 5: Expected date of delivery is higher with harmonization

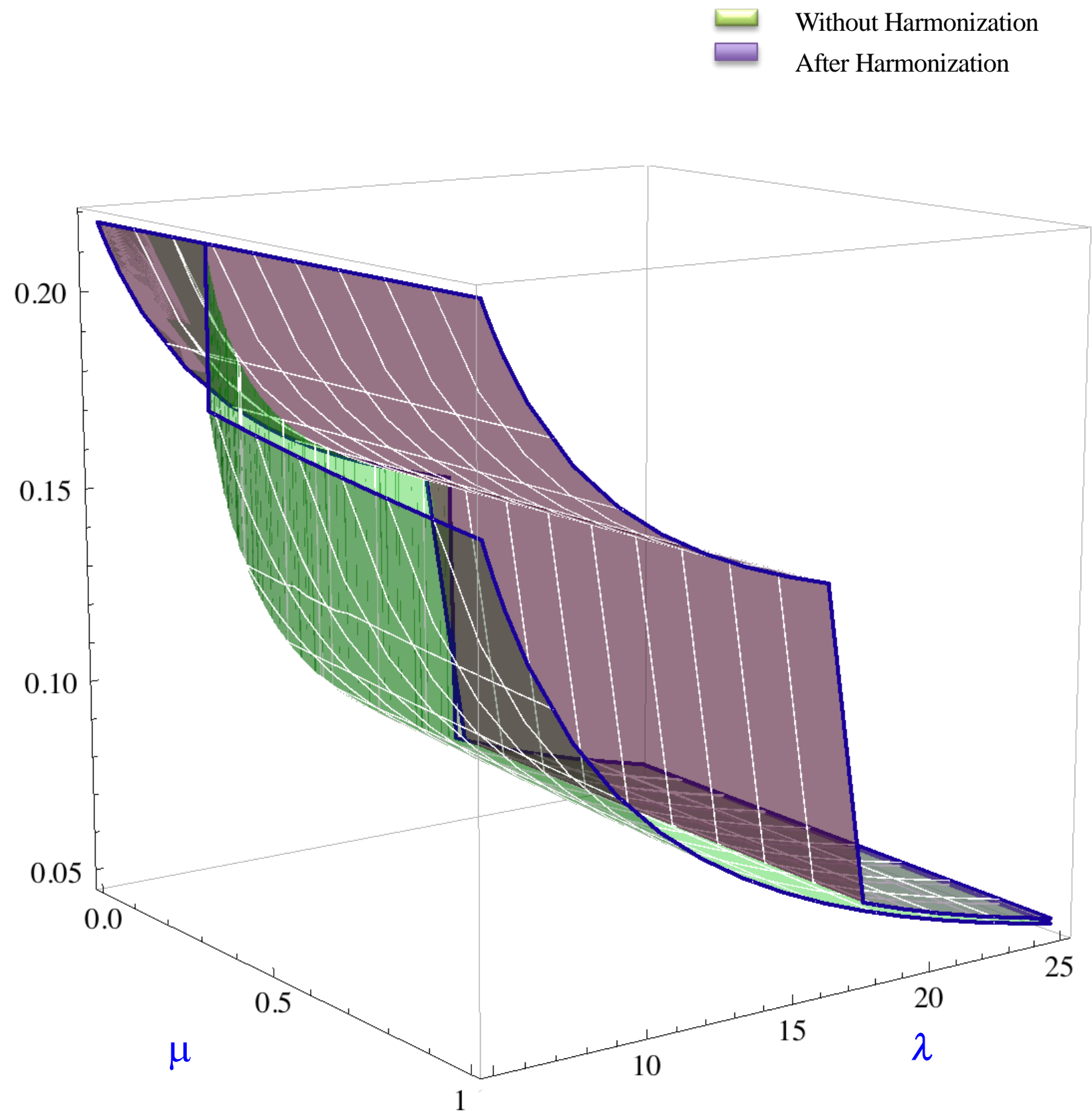


Figure 6: Expected profits of the firms is lower with harmonization

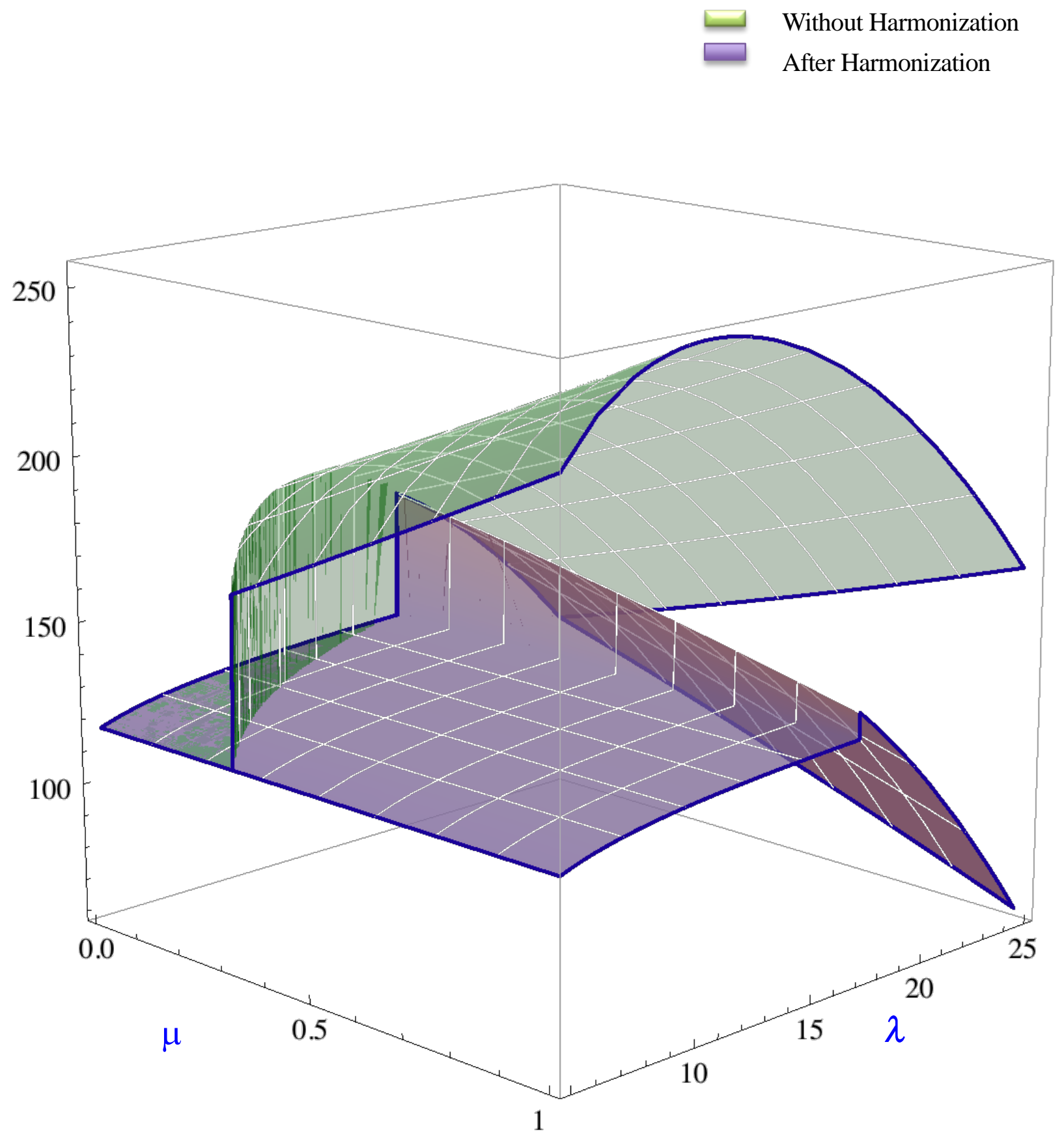

